\title{
ASPEK MANUSIA PULL/PUSH FACTORS DI PASAR BUAH JL. ANGGI SAMARINDA
}

\section{(THE HUMAN ASPECT OF PULL/PUSH FACTORS AT FRUIT MARKET ANGGI STREET SAMARINDA)}

\author{
Edith Abram Rochdi \\ Universitas Nahdlatul Ulama Kalimantan Timur-Teknik Arsitektur \\ Jl. KH. Harun Nafsi Gg. Dharma, kel. Rapak Dalam, kec. Loa Janan Ilir, \\ telp/fax. 0541-7269413, Samarinda \\ Email: unukaltim@gmail.com; edithabram_rochdi@yahoo.com
}

Diterima: 26 Juni 2018; Direvisi: 2 Agustus 2018; Disetujui: 7 Agustus 2018

\begin{abstract}
ABSTRAK
Manusia dengan berbagai aspek yang mempengaruhinya seperti tingkah laku, batas sosial, budaya dan kecenderungan menguasai wilayah atau territorial mempunyai peranan yang besar sekali dalam pembentukan dan perkembangan kota dengan pendekatan perancangan kota. Adanya kecenderungan pengelompokan oleh manusia dalam suatu areal perkotaaan berdasarkan pada pemahaman terhadap keserba samaan, penjabaran kualitas lingkungan, gaya hidup, sistim simbol dan pertahanan melawan kepadatan dan ketegangan permasalahan penduduk. Terkait dengan hal ini, pada perkembangan kota Samarinda di Kalimantan Timur ada salah satu fenomena yang timbul dengan lingkungan terbangun atau built environment yang mempunyai properti yang menurut Rapoport(1984) akan diambil alih oleh komunitas bila tempat yang ada bisa memberikan penilaian tinggi terhadap karakteristik lingkungannya atau akan ditinggalkannya bila tempat tersebut mempunyai anggapan negatif. Yang selanjutnya dapat dinyatakan sebagai pull factors dan push factors sebagai istilah yang biasa dipakai dalam Perancangan kota,

Fenomena yang ada di kota Samarinda saat ini adalah dengan masih maraknya pedagang kaki lima (pkl) yang berjualan di lokasi-lokasi terlarang di Samarinda. Adapun salah satunya yang menyolok adalah pedagang buah-buahan yang berada di sepanjang jl. Slamet Riyadi dan jalan sekitarnya. Pada perkembangannya untuk mengatasi para pedagang buah tersebut ternyata pemkot Samarinda mempunyai berbagai kendala dan masalah yang ada. Hal ini ada kaitannya dengan masalah kecenderungan para pedagang buah yang bisa dikatakan sebagai suatu komunitas tersendiri yang mampu melakukan tindakan pull factors dan push factors.
\end{abstract}

Kata kunci: Pull Factors, Push Factors, Aspek Manusia

\begin{abstract}
The human aspects influence it as like the behaviorius, the social, the culture and the control of the territorial or having an enormous role in the formation and growth of the capital city with the approach of urban design city. The tendency of grouping by people in an area based on knowledge of multifariousness, the quality of the enviroment, the lifestyle, facilities symbols and the defensence against the. population density and the tension of population. Related to this, on the development of cities samarinda in east kalimantan is one of the phenomena it with the built environment have awakened or property according to rapoport (1984) is taken by the community if there can pass judgment high evaluation characteristics of their environment or will they leave if a place had the negative perceptions of other. Which can be expressed as pull factors and the push factors in urban design.

The phenomenon in samarinda now is there are many traders who trade in the location that can not to do trading on it. One of which is at Slamet Riyadi street and the surrounding it. In its development to overcome the traders of it appeared that the city government of Samarinda has a
\end{abstract}


variety of obstacles and problems. It is the relation to the issue of the traders of that are capable of performing the act of pull factors and the push factors.

Keywords: Pull Factors, Push Factors, Human Aspect

\section{PENDAHULUAN}

Manusia dengan Sosial Budayanya mempunyai peranan penting pada lingkungan perkotaan. Kenyataannya dalam gaya hidup, alam sekitar, lokasi dan waktu dalam kegiatan masyarakat merupakan suatu cara untuk memahami aspek Sosial Budaya dalam suatu kota dan terintegrasi dengan jaringan sosial, sistim kegiatan, alokasi waktu dan kebiasaan yang ada.

Budaya menurut E.B.Tylor, 1981 didefinisikan sebagai keseluruhan yang kompleks meliputi pengetahuan, kepercayaan, kesenian, hukum, moral, adat dan berbagai kemampuan dan kebiasaan yang diperoleh manusia sebagai anggota masyarakat. Sedangkan menurut A.L Kroeber,1952 Budaya adalah keseluruhan pola-pola tingkah laku dan pola-pola bertingkah laku, baik eksplisit maupun implicit, yang diperoleh dan diturunkan melalui symbol, yang akhirnya mampu mmbentuk sesuatu yang khas dari kelompok-kelompok manusia, termasuk perwujudannya dalam benda-benda materi.

Berkenaan dengan hal diatas terdapat beberapa pedagang kaki lima (pkl) yang berjualan buah sudah sejak beberapa tahun lalu tampak ramai menguasai kawasan tepi jalan-jalan protokol di Kota Samarinda, seperti jl. RE. Martadinata-Slamet Riyadi, jl. MT. Haryono, jl. P. Suryanata dan jl. Cendana. Mereka ada yang memasang tenda terpal, pakai mobil pikap sampai menggunakan gerobak dorong. Jumlah pedagang diperkirakan mencapai lebih puluhan orang hanya untuk di kawasan jl. RE. Martadinata-Slamet Riyadi. Disini ada belasan pedagang buah berderet di tepi jalan ini yang merupakan jalan utama disepanjang koridor sungai Mahakam. Mereka yang berjualan di tepi-tepi jalan semakin marak dan padat berakibat mengganggu aktifitas lalu lintas jalan raya dan perlu direlokasi agar tidak menimbulkan kemacetan.

Dikarenakan kepentingan memfasilitasi hal tersebut diatas, maka pihak pemkot Samarinda menyediakan ruas jl. Anggi yang semula hanya sebagai jalan lingkungan berubah fungsi menjadi areal pasar buah. Pemkot Samarinda seolah tak memiliki lahan ideal untuk pedagang buah yang sebelumnya berjejal di Pasar Pagi. Pedagang buah dilokalisir ke jalan ini sejak tahun 2001 dikarenakan lokasi jualan di Pasar Pagi tak memungkinkan lagi seiring padatnya arus lalulintas saat ini.

Pasar Anggi saat ini kondisinya sudah sangat memprihatinkan dan harus dilakukan pembenahan. Perlunya akses jalan perlu diperbaiki, demikian juga warga yang selama ini tinggal di kawasan itu harus ditertibkan. Termasuk para pedagang atau warga liar juga perlu ditertibkan di kawasan Pasar Anggi. Karena tidak mungkin menghidupkan Pasar Anggi, tanpa pembenahan. Apalagi untuk pedagang buah itu filosofinya sama seperti pedagang kaki lima.

Letak Pasar Buah di jl. Anggi ini cukup strategis walaupun tidak masuk dalam jalur utama, namun dari segi pencapaian dari kota cukup dekat. Hal ini dikarenakan bersebelahan dengan Islamic Centre yang berada pada koridor pinggir sungai Mahakam dengan difasilitasi ruang terbuka yang cukup luas dan longgar. Dan juga dilengkapi dengan sarana jalan yang cukup lebar untuk kemudahan mobilitas kendaraan yang masuk kearah kawasan ini. Dengan demikian lokasi yang ada cukup memadai untuk menampung sejumlah aktifitas pedagang khususnya penjual buah-buahan. 
Pemkot Samarinda dalam hal ini sudah mewajibkan pkl atau pedagang buah hanya berjualan di Pasar Anggi, yang saat ini dibangun khusus untuk pedagang buah. Hanya saja ada pkl buah yang dibiarkan berjualan di tepi jl. Slamet Riyadi, pada akhirnya satu per satu pkl buah meninggalkan Pasar Anggi ini. Berdasarkan pengakuan mereka berjualan buah di Pasar Anggi cukup merugikan.

Pemkot tidak mau terjebak pada persoalan lama. Sebagaimana halnya pkl harus masuk kembali ke Pasar Anggi. Masalah nantinya pasar itu akan dibenahi adalah persoalan berikutnya. Pada saat ini diinginkan pkl masuk lebih dulu dengan pertimbangan pemkot tidak akan terulang lagi permasalahan yang lalu. Kini sudah memberikan fasilitas yang ada yang ternyata tidak digunakan bahkan ditinggalkan.

Sebetulnya pemkot Samarinda sudah menyanggupi permintaan para pkl untuk melebarkan jalan di samping Pasar Anggi, agar mempermudah keluar-masuk bagi kepentingan sirkulasi lalu lintas sipembeli. Jalan sudah dilebarkan dan menelan dana APBD ratusan juta rupiah, namun pkl tetap tak mau berjualan disini. Setelah itu pemkot juga membukakan median jalan di jl. Slamet Riyadi, agar pembeli bisa dengan mudah memutar kendaraan ke arah luar kota. Kondisi sekarang nyatanya mereka tetap tidak mau kembali atau pindah ke Pasar Anggi.

\section{METODE}

Penelitian menggunakan pendekatan deskriptif kualitatif. Penelitian bertujuan mendapatkan gambaran atau deskripsi secara sistematis, aktual dan akurat melalui suatu kebenaran yang ada dilapangan. Hal ini dikarenakan hal berikut:

- Kondisi objek penelitian sudah ada sebelumnya dan secara alamiah sudah tumbuh dan berkembang seperti sekarang ini.

- Pada kondisi lapangan selalu ada kemungkinan, realitas dan obyektivitas tunggal.

- Perlunya survey dilapangan secara intensif yang sangat diutamakan dalam penelitian.

- Peneliti bersifat independen atau bebas dari obyek yang diteliti.

- Dalam pendekatan penelitian, disini pada saat masuk pada objek penelitian perlu berbekal opini atau dugaan awal untuk memahami aplikasi pull factors/push factors dalam pendekatan perancangan kota.

\section{HASIL DAN PEMBAHASAN}

Menurut Kepala Dinas Pasar dan Penataan PKL Kota Samarinda Drs. HM. Ridwan Tassa, MM., bahwasanya pembahasan mengenai kondisi Pasar Anggi sebenarnya sudah ada, tapi belum ada keputusannya seperti apa nantinya dikemudian hari. Disinggung mengenai alternatif pilihan pemkot terhadap kondisi Pasar Anggi, Ridwan menegaskan hanya ada 2 (dua) pilihan, yaitu melakukan pembenahan atau membongkar petak-petak di kawasan Pasar Anggi yang sekarang makin kumuh. Dan itupun tergantung dari kajian nanti bila ternyata fisibel untuk ditata dan dikembangkan, maka Pasar Anggi tetap akan dipertahankan dan dibenahi. Tetapi bilamana dari kajian nanti tidak ekonomis maka akan dibongkar.

Sampai akhirnya ada suatu kebijakan dari pemkot Samarinda untuk mengkonsentrasikan semua pkl di sepanjang koridor atau tepian sungai Mahakam ke jl. Slamet Riadi. Disini lokasinya berupa ruang terbuka yang berada disamping masjid Darunni'mah, Sungai Kunjang, dan hal ini merupakan solusi terakhir. Kali ini pemkot membenahi lokasi tersebut dengan melakukan penghamparan batu kerikil, dimana kondisi semula hanya berupa rerumputan dan lahannya tidak rata. 


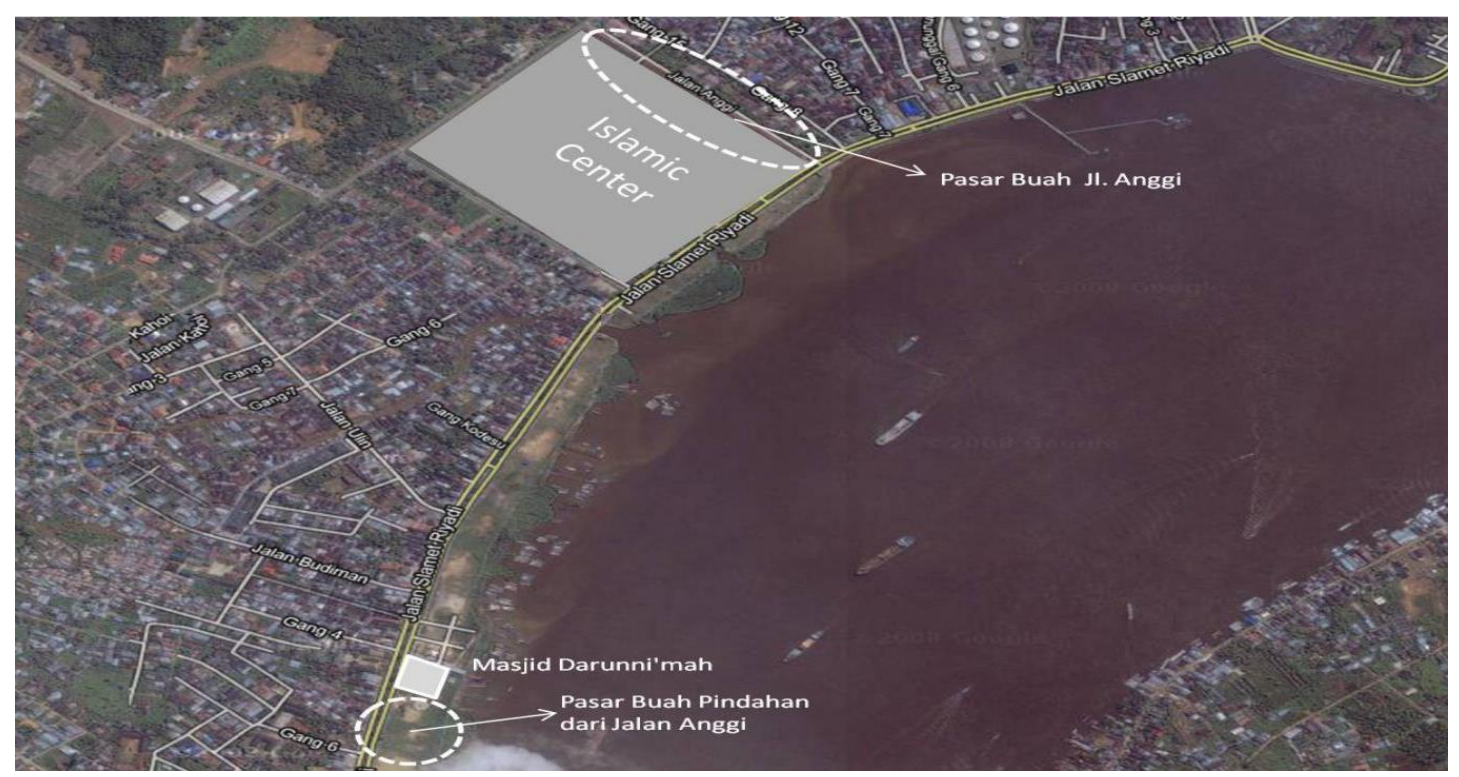

Gambar 1. Peta situasi letak pasar buah di jl. Anggi (awal) dan rencana relokasi (akhir) Sumber: Hasil survey (2012)

Langkah ini dilakukan setelah rapat koordinasi (rakor) tentang pkl Tepian Mahakam di Balaikota. Rakor itu dipimpin Wakil Walikota Samarinda, dengan mengundang Dinas Pasar, Satpol PP, Dinas Bina Marga dan Pengairan (DBMP), aparatur Kecamatan Sungai Kunjang dan aparatur Kelurahan Karang Asam Ilir.

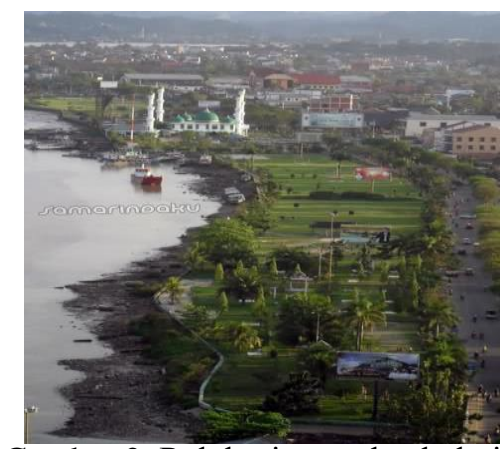

Gambar 2. Relokasi pasar buah dari j
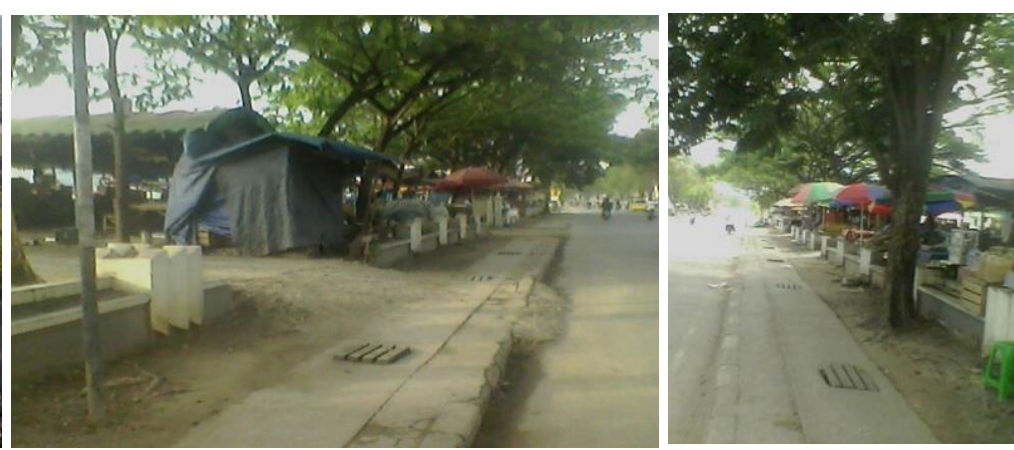

Sumber: Hasil survey (2012)

Ternyata langkah Pemkot dalam upaya membenahi lokasi itu cukup berhasil. Aktifitas jual beli buah menjadi hidup yang membuat para pkl semakin betah berjualan. Dengan melihat pengalaman seperti Pasar Buah di Jl Anggi (samping Islamic Center) dengan akses jalan masuk mengalami rusak parah menyebabkan pengunjung enggan masuk. Akhirnya pkl meninggalkan Pasar Anggi yang semula menjadi pusat pedagang buah. Kalau akses masuk mudah dijangkau pembeli, maka pengunjungnya pasti ramai. Dan ini upaya pemkot menghidupkan lokasi pemusatan pkl di tepian Mahakam. Kondisi jl. Anggi di kelurahan Teluk Lerong Ulu, Sungai Kunjang yang menghubungkan ke jl. Slamet Riadi dan jl. Cendana pasca pkl pindah ketempat baru kian memprihatinkan. Tak hanya berdebu saat musim panas, saat hujan kondisinya malah lebih parah. 


\section{Edith Abram Rochdi}

Dikonfirmasi terhadap hal ini, kepala Dinas Bina Marga dan pengairan (DBMP) Kota Samarinda, Ir. Dadang Airlangga, MMT. kepada Sapos mengakui pentingnya akses jl. Anggi. Selain diperuntukkan untuk jalan alternatif, juga difungsikan sebagai penunjang parkir Islamic Centre. Dikarenakan jalan tersebut masuk dalam daftar prioritas perbaikan bagi pihak pemkot Samarinda. Kondisi saat ini jl. Anggi sudah tidak menjadi tempat kumuh lagi, tapi sudah menjadi bagian jalan akses dari kawasan Islamic Centre yang menghubungkan jalan primer dengan jalan secunder dan berfungsi sebagai pemecah kemacetan terhadap 2 (dua) arah jalur jalan.

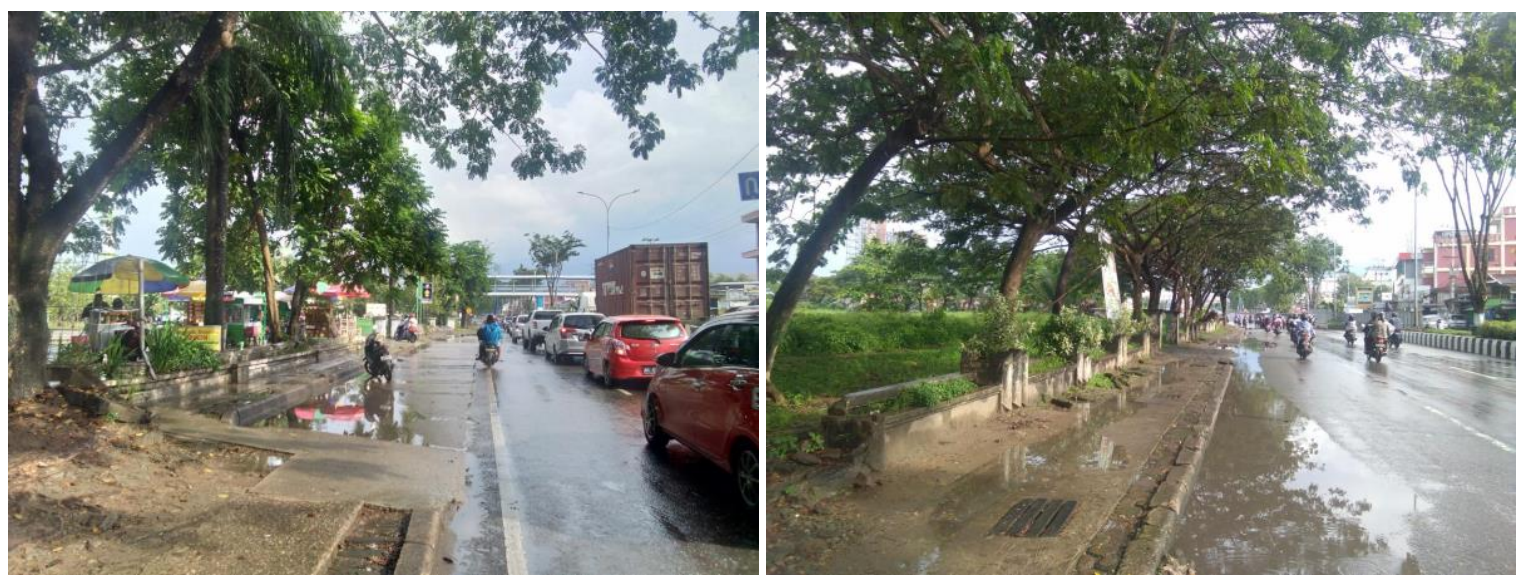

Gambar 3. Kondisi sekarang pasar buah yang direlokasi dari jl. Anggi ke sebelah Masjid Darunni'mah Sumber: Hasil survey (2018)
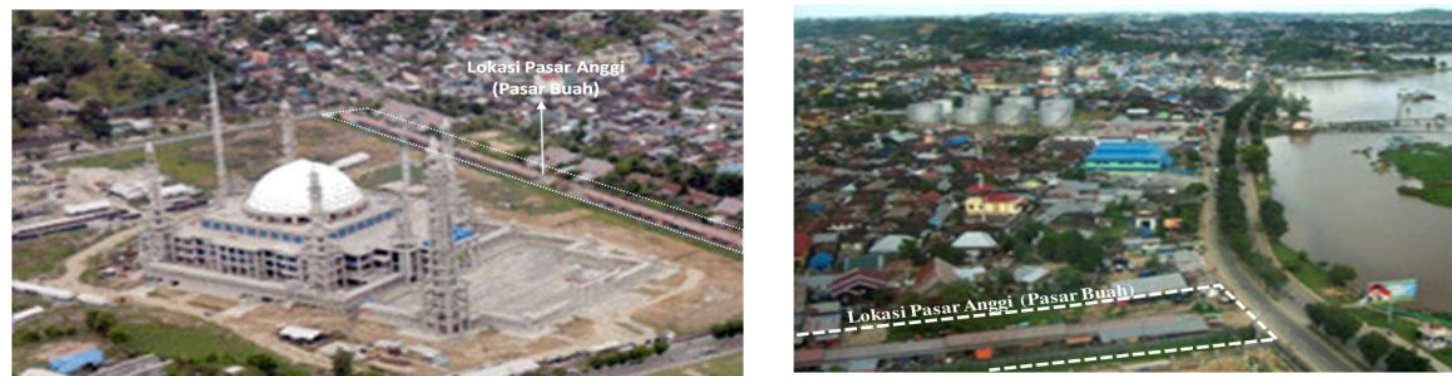

Gambar 4. Kondisi dulu pada jl. Anggi sebelum dilakukan relokasi Sumber: Hasil survey (2012)

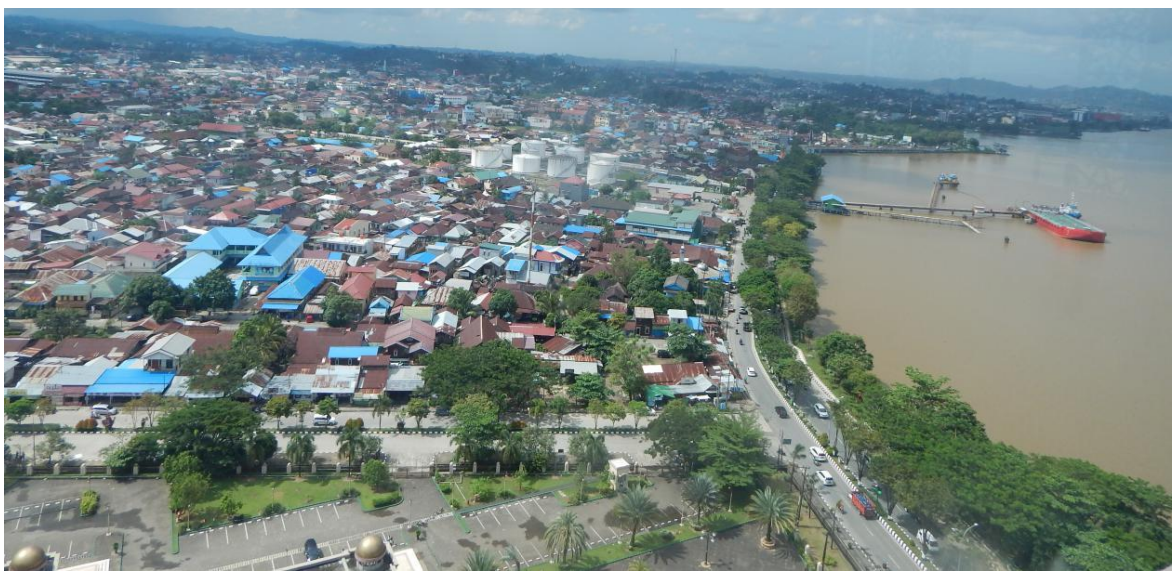

Gambar 5. Kondisi sekarang pada jl. Anggi setelah dilakukan relokasi Sumber: Hasil survey (2018) 
Seiring dengan perkembangan pembangunan kota Samarinda terfokus pada koridor sungai Mahakam, saat ini era konstruksi untuk jembatan penyambung maupun jembatan kembar sedang berjalan. Lokasi sekarang pasar buah disebelah masjid Darunni'mah yang merupakan relokasi dari jl. Anggi masuk dalam kawasan era konstruksi jembatan baru tersebut terpaksa harus dihentikan sementara. Kegiatan pasar buah akhirnya menyebar lokasinya kemana-mana baik dekat lokasi yang ada maupun agak berjauhan letaknya, atau bahkan berjualan buah dipinggir jalan dengan menggunakan mobil pikap.

\section{KESIMPULAN}

Pada dasarnya karakter para pedagang buah dengan ciri khas sebagai pedagang kaki lima atau pkl, merupakan suatu komunitas tersendiri dan sangat spesifik dengan apa yang dijualnya. Komunitas ini akan mencari tempat yang akan sangat menguntungkan bagi kelompoknya sendiri dalam hal berjualan. Disini mereka akan menempati suatu wilayah atau teritorial yang ada sepanjang bisa meningkatkan taraf hidup dalam hal pendapatannya. Dengan demikian faktor ekonomi sangat berpengaruh dalam kegiatan rutin sehari-hari pada komunitas ini. Disamping itu untuk para pembeli berperan pada keberhasilan komunitas ini dalam menjual barang dagangannya kepada mereka. Hal ini sangat dipengaruhi oleh aksesbilitas dan struktur jalan yang melewati areal berjualan atau berdagang buah-buahan. Hal ini ada kaitannya dengan kemudahan pencapaian, arah aliran lalu lintas dan pergerakan sirkulasi pembeli yang akan berangkat atau pulang kerja dan sarana kendaraan yang rata-rata memakai kendaraan bermotor dengan kemudahan pemarkiran kendaraannya dan kemudahan mobilitas lainnya.

Terfokus pada pasar buah yang berlokasi di jl. Anggi ini merupakan suatu produk kegagalan pemerintah kota Samarinda dalam upaya menertibkan para pedagang buah atau pkl yang ada. Lokasi yang disediakan telah ditinggalkan oleh komunitas pedagang buah dan berupaya mencari tempat lain yang lebih menguntungkan secara ekonomis. Lokasi ini merupakan suatu contoh push factors, dengan kondisi komunitas terkait meninggalkan areal ini atau menarik diri karena lokasi ini memberi penilaian negatif terhadap karakteristik lingkungannya. Tentunya hal ini mempunyai suatu alasan tertentu. Pandangan negatif pada lingkungan yang ditempatinya terjadi oleh sebab potensi lingkungan itu sendiri yang kurang memberikan nilai ekonomis. Bila melihat lokasi di jl. Anggi, karakteristik lingkungan tidak cukup mendukung kegiatan komunitas yang ada. Para pembeli mengalami kesulitan untuk berbalik arah menjangkau lokasi tersebut dikarenakan arus pembeli banyak dari arah lalu lintas yang akan pulang kerja menuju tempat tinggalnya masing-masing. Sehingga tempat ini menjadi sepi pembeli mengakibatkan pedagang mengalami kerugian dan terisolir dalam aksesbilitas pencapaian kelokasi tersebut. Hal ini menjadi suatu alasan pokok bagi pedagang buah untuk meninggalkan tempat yang ada.

Kemudian bila melihat pada kondisi sekarang sebagai hasil relokasi pasar buah dari jl. Anggi yang berada pada koridor sungai Mahakam terjadi lagi peristiwa push factors. Hal ini dikarenakan lokasi tersebut tergusur akibat kegiatan konstruksi jembatan kembar Mahakam beserta jembatan penyambungnya dalam 2 (dua) arah sekaligus untuk sementara waktu sampai proyek tersebut selesai dan difungsikan kegiatannya.

\section{REKOMENDASI}

Realisasi penempatan lokasi baru Pasar Buah pada koridor sungai Mahakam di sebelah masjid Darunni'mah merupakan suatu keputusan dan pertimbangan yang cukup baik dari pihak pemkot Samarinda. Hal ini dikarenakan tempat ini jadi berkembang nilai ekonomisnya 
dengan banyaknya pembeli yang datang ke tempat ini. Lokasi ini memberikan contoh pull factors dengan kondisi komunitas tertentu akan mengambil dan atau memilih tempat yang mereka berikan penilaian tinggi karakteristik lingkungannya.

Karakteristik lingkungan ini bisa memberikan nilai lebih dikarenakan oleh adanya pengaruh:

- Lokasi yang strategis termasuk struktur ruang terbukanya, sehingga pedagang buah dapat berjualan tanpa mengganggu kemacetan jalan raya.

- Keterdekatan lokasi dengan jalan raya atau utama yang lalu lintasnya searah pada saat pembeli pulang kerja dan menuju tempat tinggalnya, sehingga pembeli tidak memutar arah.

- Kemudahan pemarkiran kendaraan bermotor bagi para pembeli.

- Kepraktisan para pembeli dalam berbelanja dan membeli buah-buahan.

- Menjadikan tempat yang baru ini sebagai sarana rekreasi tambahan dan pemanfaatan ruang terbuka yang sebelumnya tidak memberikan nilai ekonomis pada saat pasar buah belum dilakukan relokasi, dikarenakan keterdekatannya dengan tepi sungai Mahakam.

Dalam hal ini komunitas pkl (pedagang kaki lima) dapat memberikan penilaian positif maupun negatif terhadap karakteristik lingkungan yang ditempatinya. Disini ada kecenderungan memilih untuk akan terus menempati (pull factors) atau meninggalkan begitu saja (push factors). Hal ini berpedoman pada kualitas lingkungannya sebagai hal yang utama. Sedangkan kuantitas lingkungan tidak akan berpengaruh selama karakteristik lingkungan tersebut tidak menguntungkan bagi peningkatan kualitas hidup suatu komunitas tertentu. Hal ini terlihat pada kasus pasar buah di jl. Anggi, walaupun tempat ini secara kuantitas berupa penyediaan fasilitas terpenuhi dengan baik, tapi secara kualitas untuk menumbuhkan kegiatan ekonomi tidak berhasil. Disini justru berhasil pada relokasi yang baru meskipun fasilitasnya hanya seadanya saja, tanpa difasilitasi sarana kios dan lainnya.

Mekipun keadaannya sekarang lokasi tersebut sudah tergusur untuk sementara waktu, namun dimasa yang akan datang perlu perhatian dari pihak Pemkot Samarinda dalam peningkatan sarana prasarana yang memadai pada koridor sungai Mahakam yang ada ini. Sebaiknya bila pembangunan konstruksi jembatan kembar selesai maka lokasi pasar buah bisa dikembalikan seperti semula pada koridor sungai Mahakam tersebut. Hal ini bertujuan untuk meningkatkan kualitas lingkungan dan mengembalikan sekaligus meningkatkan pull factors yang mengarah pada masalah Capital Investment. Dengan demikian pada lokasi ini akan terdapat perkembangan ekonomi yang memadai bagi pkl (pedagang kaki lima) dan peningkatan PAD bagi pemkot Samarinda. Dan tentunya dalam peningkatan fasilitas tersebut diiringi dengan penataan dan penyediaan kios, atm drive thru, lansekaping dan penanaman vegetasi yang menyatu dengan tepi sungai, mengingat lokasinya masuk dalam koridor sungai Mahakam. Hal ini perlu ditata secara keseluruhan menyatu dengan konsep kota Samarinda sebagai kota air sebagaimana rekomendasi berikut ini yang disesuaikan dengan pengembangan fisik jembatan kembar Mahakam nantinya bila sudah selesai masa pengerjaan konstruksinya.

\section{UCAPAN TERIMAKASIH}

Diucapkan terima kasih untuk Dewan Redaksi yang memberikan kesempatan untuk dapat dimuat dalam Jurnal Riset Kaltim ini, segenap civitas akademika UNU Kaltim, dan ibu Prof. Ir. Endang Titi Sunarti BD. M.Arch., Phd selaku dosen pengampu mata kuliah Aspek Manusia Dalam Bentuk Kota-S2 Arsitektur ITS Bidang Keahlian Perancangan Kota. 


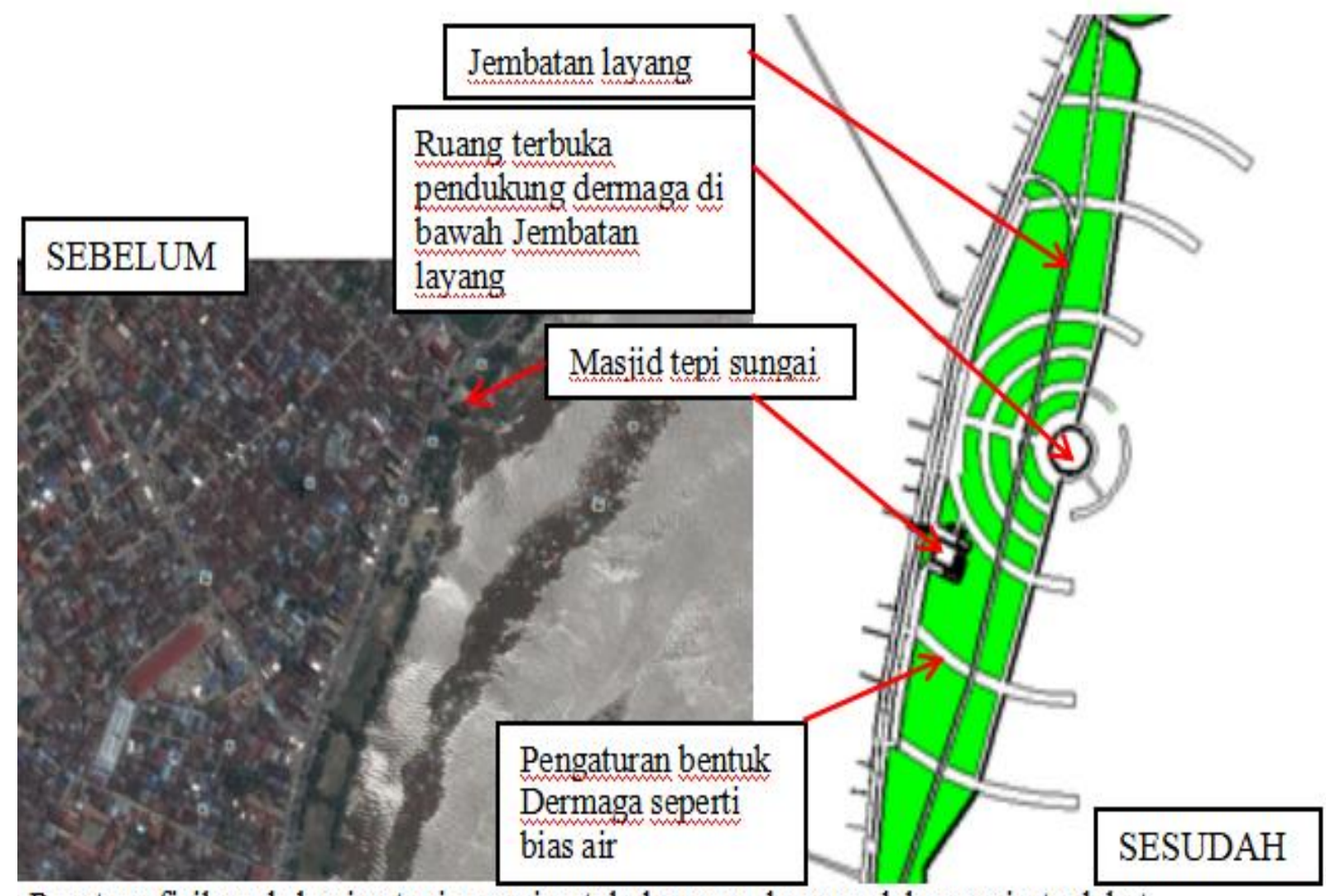

Penataan fisik pada bagian tepi sungai untuk dermaga dan mendukung wisata dekat Masjid Darunni'mah

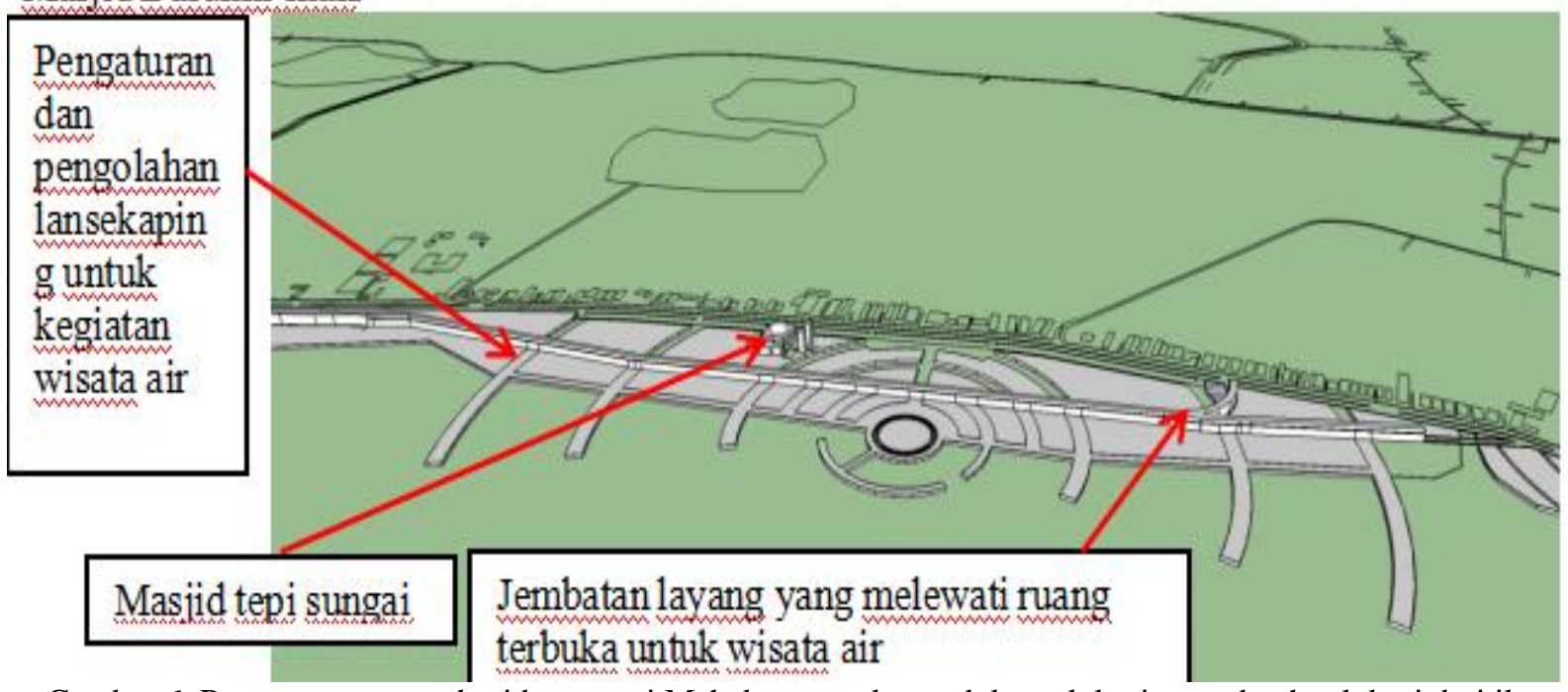

Gambar 6. Rencana penataan koridor sungai Mahakam untuk mendukung lokasi pasar buah relokasi dari jl. Anggi, Sumber: Hasil gagasan ide pribadi (2015)

\section{DAFTAR PUSTAKA}

Amos Rapoport, (1977). HUMAN ASPECTS OF URBAN FORM. Towards a ManEnvironment Approach to Urban Form and Design. Page 81-85. Pergamon Press. New York.

Bappeda Samarinda. (2013). Progres RTRW Provinsi Kalimantan Timur. Dari http://www.bappeda kaltim.RTRWP Publish.co.id, diakses pada tanggal 27 Juni 2013. 
Darjosanjoto, Endang TS, (2006). Penelitian Arsitektur Di Bidang Perumahan Dan Permukiman. Cetakan pertama. ITS press. Surabaya.

Faqih, Muhammad dan BD, Endang Titi Sunarti dan Rochdi, Edith Abram. (2016). Penataan Distrik Berkarakter Kota Sungai di Makroman Samarinda. Jurnal Berkala Ilmu Ekonomi-Neo Bis, 10(1), 91-104.

Pemerintah Samarinda Kota. (2002). Revisi Rencana Tata Ruang Wilayah (RTRW) Kota Samarinda Tahun 1994-2004. Dari http://www.perpustakaan bappenas.go.id, diakses pada tanggal 9 Maret 2014.

Parsons, Adam. (2010). Site : Serial Views. Dari adamparsonsdesignthesis. blogspot.com/2010/12/site-serial-views.html, diakses pada tanggal 24 Februari 2015.

Pemerintah Samarinda Kota. (2011). Rencana Tata Ruang Wilayah (RTRW) Kota Samarinda Tahun 2011-2031. Dari http://www.scribd.com/document/329594606/perda-RTRWkota-Samarinda, diakses pada tanggal 9 Juli 2018.

Rochdi, Edith Abram. (2015). Penataan Koridor Sungai Mahakam di Kota Samarinda, Kalimantan Timur. Tesis Program Pascasarjana Bidang Keahlian Perancangan Kota Jurusan Arsitektur FTSP ITS Surabaya.

Rochdi, Edith Abram. (2017). Penataan Ruang Terbuka Bigmall Samarinda Agar Berkarakter Kota Sungai. Jurnal Riset Kaltim, 5(2), 155-168. 